\title{
From further to higher education: transition as an on-going process
}

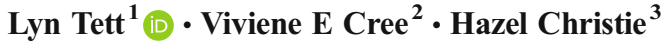

Published online: 27 December 2016

(C) The Author(s) 2016. This article is published with open access at Springerlink.com

\begin{abstract}
This paper argues that transition is not a one-off event that occurs when students first enter universities but is an on-going process that is repeated over time. We draw on qualitative data from a longitudinal project on "non-traditional" students who entered a research-intensive university in Scotland direct from further education colleges. This cohort of 45 was asked about their views on college and university learning in a study that was conducted throughout their time at university; a sub-sample of 15 was then followed up 10 years later. Our data suggest that four significant transitions, or set of critical moments, can be identified: the loss of a sense of belonging on coming to university, learning to fit in by the end of the first year, changing approaches to learning and belonging in the final years of study and changing selves in the years following graduation. At each point, positive relationships with peers and staff made a significant difference to how these transitions were managed. Moreover, the changes experienced continued to have an impact on the personal and professional lives of the cohort.
\end{abstract}

Keywords Transition processes $\cdot$ Belonging $\cdot$ Relationships $\cdot$ Changing selves

Lyn Tett

1.tett@hud.ac.uk

Viviene E Cree

viv.cree@ed.ac.uk

Hazel Christie

hazel.christie@ed.ac.uk

1 School of Education and Professional Development, University of Huddersfield, Queensgate, Huddersfield HD1 3DH, UK

2 Social Work, School of Social and Political Science, University of Edinburgh, Edinburgh EH89LD, UK

3 Institute for Academic Development, University of Edinburgh, Edinburgh EH89AL, UK 


\section{Introduction}

In Scotland, more than $50 \%$ of school leavers go onto higher education (HE). However, this overall figure hides significant variation in participation because the proportion of first-degree entrants from the most disadvantaged socio-economic groups (4 to 7 ) is only $34 \%$. This stratified entry is mainly the result of the differences in qualifications that are obtained by school leavers, because those who live in the $10 \%$ least deprived areas gain significantly better entry qualifications than those from the $10 \%$ most deprived areas (Scottish Funding Council 2015). Since entrance qualifications are set by each university and within each subject area, and Scotland's 19 HE institutions are very stratified; this means that the four "elite", research-intensive, institutions with highly selective entry standards are unlikely to admit individuals from disadvantaged backgrounds. On the other hand, the six least research-focused universities are more concerned with recruiting students and so are more likely to accept lower qualifications.

Another feature of the Scottish system is that retention rates are high overall, with a rate of over $95 \%$ in the most selective universities to less than $80 \%$ in the least selective (Scottish Funding Council 2015). Although the school-leaving qualifications ("Highers") are the most common HE entry requirement, there are other, more vocational, qualifications (Higher National Certificates and Diplomas), which can be studied at further education (FE) colleges. These institutions offer courses for people aged over 16 mainly leading to work-related qualifications that use unit-based assessment and offer articulation routes into some degrees. However, these qualifications have historically been regarded as "non-standard" in the most selective universities (Field 2004)

The case on which this paper is based is unusual because it is focused on an elite university that admitted a cohort of students with vocational qualifications directly from FE into degree programmes within humanities and social sciences as part of this university's commitment to widening access (Cree et al. 2006). This means that these students are "non-traditional" for the case-study university because of their entry qualifications and because they are not school leavers. Many of them were also of mature age. This paper is therefore concerned with this group's experiences and the transitions that they made as an example of how non-traditional students fare. Before we turn to our specific case, however, we consider existing research on non-traditional students and transitions.

\section{Transitions and non-traditional students}

There is an extensive literature that investigates transitions into the first year of university by school leavers (e.g. Brooman \& Darwent 2013; Scanlon et al. 2007) and more limited research on non-traditional students (e.g. Bathmaker \& Thomas 2009; Clayton et al. 2009). However, there is little research that has considered the perspective of students themselves (see Bowles et al. 2014) or that has tracked such transitions over time (see Donche et al. 2010). The study discussed in this paper is designed to address this gap in the literature in a way that will focus on "the interplay between the social and academic circumstances of students and the institutional systems that should support them" (Briggs et al. 2012, 4). 
Our research is framed by a socio-cultural perspective mainly derived from Lave \& Wenger (1991) where learning and identity are characterised as not only about mastering the techniques and tools characteristic of a practice but also about becoming embedded in the social structures of that practice. Lave and Wenger's theory emphasises "the inherently socially negotiated character of meaning and the interested, concerned character of the thought and action of persons-in-activity...in, with, and arising from, the socially and culturally structured world" (1991, 50-51). From this perspective, significant learning is what changes our ability to engage in practice and to understand why we do it. Such learning is not just the acquisition of habits and skills, but also the formation of an identity that involves developing shared values, assumptions and purposes with others in our community of practice (Wenger 1998).

Using this socio-cultural lens also leads to a particular understanding of learner identities, because the emphasis is placed on understanding dispositions to learning as part of a social process of identity formation (Reay et al. 2010). In other words, learning is seen as sensitive to biographical narratives and cultural influences, is embodied and relational and comes about through "the integration of product and process" (Hodkinson 2005, 116). So, non-traditional students entering university may not have the socio-cultural capabilities necessary to identify, understand and assimilate a complex range of assumptions, behaviours and practices "often tacitly represented by the range of disciplines, or fields, they are studying" (Hussey \& Smith 2010, 159). This means that becoming a student may entail undoing earlier understandings as a new environment with different cultural assumptions and learning and teaching styles is entered (Christie et al. 2008; Leese 2010). Students' predispositions and expectations then have a significant impact on their experience, especially if they do not feel that they belong in the university environment (Solomon 2007). Some changes can involve upsetting experiences, leading to feelings of vulnerability and insecurity. Others are positive and can engender feelings of hopeful anticipation (Griffiths et al. 2005). Thus, the acquisition of a positive learning identity is complex and contradictory: evoking powerful feelings of displacement and guilt, alongside hopeful anticipation and pleasure (Crossan et al. 2003; Bathmaker \& Thomas 2009). This suggests that education is not an "embellishment to" or "accomplishment of" a self whose personal qualities and characteristics are fixed, but rather, education is shaped by educational discourses and by the relations between "self, other and text that take place in educational contexts" (Saltmarsh \& Saltmarsh 2008, 622).

Much of the existing literature starts from the premise that transition is a process of induction leading to sequential periods of adjustment, but as Gale \& Parker (2014: 737) argue, it is more about "whole-of-life fluctuations in lived reality or subjective experience". Using a socio-cultural lens leads to the conceptualisation of transition as a process that takes place over time, continuing well beyond entry to the university, and involves changes that are navigated by students as they move through formal education and beyond (Bowles et al. 2014; Hussey \& Smith 2010). Becoming and remaining a successful student are, therefore, not just about meeting the requirements set by institutions but are embedded in the totality of students' experiences throughout their academic career (Donche et al. 2010). It is concerned with how students navigate through their experiences and how this has an impact on their identities. 


\section{Methodology}

In the light of the gaps identified in the literature, we sought to address two research questions:

- What do a cohort of non-traditional students' perceive to be the key transitions that they experience on entry to, and during, their university studies?

- What do the cohort perceive to be the impact of their studies on their identities?

The data were derived from in-depth, semi-structured interviews (lasting around an hour) undertaken with participants at key points during their degrees. All were studying subjects in social sciences and humanities and had gained entry to the university on the basis of Higher National Qualifications from FE colleges. All 70 students were invited to participate, and 35 were recruited to the study in 2004, and in the following year, an additional 10 students (out of 30) joined the study in order to increase the range of subjects being taken. Table 1 sets out the five collection points at which the students were contacted between the beginning and end of their studies. The aim was to find out from the students themselves how they were faring with a primary focus on the transitions that they were undergoing at that point in their studies. The topics explored included the following: views about teaching and learning environments, assessment and feedback practices, relationships with peers and staff and work-life balance. Most students (82\%) were women, and just under half (49\%) were over 30 years of age (see Table 2).

In 2015, we attempted, through alumni registers, to contact the cohort 10 years after they had started their studies. Of the 16 that we found, 15 were willing to be interviewed. Table 3 shows the age and sex of these interviewees. All but one of the respondents were women, reflecting the female bias of the original sample. The spread of age ranges was similar to that of the initial cohort of 45 , with the majority being between 31 and 40 when they started their degree. During this final interview, we invited participants to reflect back on their whole experience of university and any impact that their studies had had on their subsequent personal and professional lives.

Each interview was recorded and fully transcribed and was sorted with the NUD-IST software. Our analysis of the transcripts employed the constant comparative method (Braun and Clarke 2006). To do this, we identified themes from the literature including the lack of tacit knowledge of the university system (Leese 2010), the challenges to secure identity formation (Reay et al. 2010) and the emotions generated by changing identities (Bathmaker \& Thomas 2009). We then not only sought

Table 1 Schedule of interviews from start to completion of studies

Time when interview took place

First interview

Second interview

Third interview

Fourth interview

Fifth interview
Week before university studies started (commonly called "Freshers Week")

End of semester one, 1st year

Beginning of 2 nd year

Beginning of 3 rd year

Beginning of 4 th year 
Table 2 Age and sex of informants in the original study $(n=45)$

\begin{tabular}{lcc}
\hline Age & Female & Male \\
\hline Under 20 & 7 & 4 \\
$21-30$ & 6 & 4 \\
$31-40$ & 18 & 0 \\
$41-50$ & 4 & 0 \\
$51-60$ & 2 & 0 \\
Total & 37 & 8 \\
\hline
\end{tabular}

instances of these in the interview transcripts but also paid attention to new themes that arose. These new themes included the role of peer support, the importance of staff-student interaction, managing academically and the growth of self-esteem.

Each data item was given equal attention in the coding process; themes were checked against each other and back to the literature. This method of analysis had the advantage of giving a holistic picture rather than a fragmented view of individual variables. Inter-rater reliability was checked by each research team member individually coding a section of text, and then, the percentage of agreement was assessed. Only where this was above $70 \%$ was a category selected in order to ensure consistency.

The data from the interviews conducted 10 years on required sensitivity to the possibility of recall bias, which represents a threat to the internal validity of studies using self-reported data (Hassan 2005). In order to counter this, we firstly gave respondents a copy of the questions in advance to help them with their recall, and secondly, by reviewing our original data set, we checked that what they said in the retrospective interview was consistent with what they had said during the interviews undertaken when they were at university.

Our analysis of these data showed that students' experience of transition was most commonly expressed in terms of a set of critical moments (Higgs et al. 2001), and we have used these moments to structure the paper. Critical moments occurred: at the beginning of first year; at the end of first year/beginning of second year and in the third and fourth years. The final transition occurred after graduation as the former students looked back on their university experiences from a distance. Throughout the empirical sections, we have selected quotations from the students that best represent the themes that were common to each of these critical moments in the transition process.

Table 3 Age and sex of informants in the follow-up study $(n=15)$

\begin{tabular}{lcc}
\hline Age & Female & Male \\
\hline Under 20 & 2 & 1 \\
$21-30$ & 2 & 0 \\
$31-40$ & 8 & 0 \\
$41-50$ & 1 & 0 \\
$51-60$ & 1 & 0 \\
Total & 14 & 1 \\
\hline
\end{tabular}




\section{Findings}

\section{Making the first transition: the loss of a sense of belonging}

\section{Initial expectations}

In their initial interview, undertaken during "Freshers Week", most students commented on how much they were looking forward to their time at the university. Almost all expressed this as a strong sense of exhilaration and excitement, for example,

I think at university obviously, people are here to study because this is what they wanted to do and they have a thirst for knowledge and I think that's going to be good (02). Just the full experience of it...that growing, you know?...I'm 36 and sometimes I feel 16, so I'm looking to help...my own self-confidence, just establishing what I know and building on that (39).

\section{Uncertainties}

In the second interview, at the end of the first semester, a clear majority of students faced with the reality of studying described the process of transition as difficult because they felt uncertain about what was expected of them. There were several components to this. One was about being known and knowing your community:

All the lecturers [in FE] learnt everyone's name... [as well as] student services. There was always someone to go and...speak to. [The University] feels so much bigger...it's all spread out and there are people everywhere. [In] college... you recognise people... but here it's not like that (13).

Another uncertainty was about the availability of, and contact with, staff. For example, student 22 described her first semester experience as being told:

"Go away and get on with it and come back like two weeks on Tuesday and I'll see you". She compared this with FE' where anything you wanted to know...you could call the tutors up or you could go in.... They were always available.

In FE, they had also felt supported by their peers as student 07 pointed out:

My classmates supported me and I supported them. If I researched something I'd photocopy it and give it out.

\section{Standards and feedback}

A clear majority of the students commented on the problem of anticipating the standard of work required and the support that would be available. For example,

I didn't really know what was expected. Academic writing in comparison to college is completely different (10) and

There is that uncertainty. Am I really on the right road? (25). 
Students also had problems in deciphering lengthy reading lists - where to start, how many of the books and articles to read and so on, and this could also lead to a crisis of confidence in this unfamiliar learning environment. For example,

It was clear to us what we had to do [for an essay]...but it was just never knowing if it was right. Is this what they were expecting of someone who is supposed to be of university standard? (32).

Another unsettling factor was the timing of feedback. One student contrasted the response time of the staff in FE where she had handed in her essay to her tutor, and it had been returned the next day with comments that they would discuss face-to face. Whereas in her first semester at university, she said:

I never saw my tutor again after I got my first assessment in the first semester, because she took a long, long time to actually get them back to us; so we never ever got a chance to speak to her (04).

A few students also interpreted their feedback personally even though all assignments were marked anonymously. For example,

I got a [low mark and] I wasn't very impressed and then she wrote these comments about you should have mentioned this, this and this....and I just didn't understand her reasoning at all...I just got the general feeling that there wasn't much love, so to speak (05).

A few students felt that the contrasting experiences in university were really positive.

I've loved the lectures and I mean you just feel like “oh, I didn't know that", so it's like you're getting information all the time (14).

Around half felt that FE was a bit overprotected:

You were more nursed through it than you are at university (12).

However, for a clear majority coming to university was a "learning shock" (Griffiths et al. 2005) where the loss of support and embedded knowledge undermined their self-confidence.

\section{Making the second transition: learning to fit in}

\section{The role of peers}

By the end of their first year, a clear majority had learnt that at university,

You have to be more self-motivated (05)

Being part of a much larger cohort meant that there was little possibility of getting to know all the staff easily. At this point, almost all realised the importance of meeting other students with whom they could share the university experience. One student suggested the following:

It took the whole of the first semester to realise how important it is to talk to each other and share because... it has really made such a difference (04) 
Another showed the importance of sharing your own doubts with peers:

I really dipped in the first term... but having spoken to different people that seems to be a very common thing. [So] I came back in term two with a....renewed determination (25).

Around half suggested that support from peers was best when they were involved in discussions:

Because you learn from each other... and everybody discusses different things (37).

Peer friendships were also important when students were struggling with their work:

Sometimes I feel that I shouldn't be here because I do struggle and I can see that some of the other people are taking it all in, while I am struggling and all the rest of it. But because the people in the class are so nice, it's OK (35).

Another spoke of the way, she had been given the following:

A bit of a push to get rid of the self-doubt (22) by her peers.

Almost all of the students on discovering that they were not the only older person on their course felt more part of the community:

I can see I'm certainly not the only mature student around and I have made a lot of friends (20).

However, a few felt that they did not fit in amongst the "young ones" who might seem more much confident, especially at first. The majority of students realised, however, as they settled into their courses that they had important contributions to make and this led to them seeing themselves differently:

I feel I am as entitled to be there as anybody else as my life experiences have all contributed to me being here (04).

Working together on group projects was also important.

Our study group made a difference [because] when you've got somebody that you can say, "oh I never took that from that", or "I never thought they meant that" it helps you to understand (22).

\section{The role of tutorials}

A few students reported that they were more inclined to speak to other students than to academic staff about their difficulties.

If I have a question or [when we are] working together, it's really peers that we work with.... Although my confidence is quite good, just to put a couple of questions up and see who gets back to you...It is quite good to have that (13).

For the majority, however, the tutorials played an important role as the year progressed. This was because they allowed students to

bounce ideas off each other (07)

This aided understanding and reinforced what they had learned in lectures. Students also spoke about the importance of sharing ideas and listening to different points of view. 
In my [tutorial]...we have that varied knowledge base and experience base, so you're always learning from each other (38).

These discussions helped not only because students were hearing others' points of view but also meant

You can think your own ideas through and if you can verbalise ideas...it essentially means that you understand them and if you can speak them, you can probably write them down as well. So that's really good (27).

Others found that talking to tutors and lecturers and fellow students made a real difference:

You get to know people and that really helps because obviously if you enjoy it, you want to achieve your goals,...you're wanting to find out more and how to do it better (09).

\section{Managing academically}

Managing academically was also crucial in helping students to feel part of the university community:

At the beginning it was like muscling in on the kids... [but] once I got more into the swing of how things worked, where I was going, passing my exams, slotting in, [I felt] yeah, you should be here (22).

Receiving (good) marks and feedback on course work helped the students to increase their self-confidence:

I feel more like a university student than I felt in the past. I have got my first essay marks back and I have passed so I feel that I am in the right place (38).

This was seen by a few as a collective experience:

We all did really well on our first assignment so that gave us a boost that we all know where we are going now and that we are on the right lines (37).

Students also learned that they could manage difficult and complicated schedules but it was not easy.

It's been difficult having two assessments at almost the same time and having to balance it with work and family, and trying to get in and out of [university]. But from a personal point of view it is gratifying to be doing something like this (35).

\section{Accessing staff support}

A factor in moving towards significant learning was for the students to recognise what support was available from academic staff and to learn how to access it proactively:

If there was something you did not understand you could just go and talk to them, and they were not stand-offish as I thought that they would be. That surprised me (07).

Sometimes, the role of staff was seen more ambiguously:

[Staff] are very approachable but you don't always get the answer you're looking for (13). 
This ambiguity was partly to do with different expectations as one student pointed out:

If you ask them, they'll be more than happy to help you... whereas [before in FE] they'd like come and throw themselves at you (02).

\section{Support from family and friends}

Outside of the university, some students got both emotional and practical support from their family and friends that helped to confirm that they were doing the right thing:

My partner [helped me to succeed]...she's just finished her degree in nursing and she's taught me a lot of good habits (27).

Sometimes, the help was more ambiguous:

He [husband] is trying to help me a bit you know but [his attitude] is "I don't like you going to university because you don't care about us any more"... and the kids are sort of "oh, if you have to", you know (22).

And in other cases quite negative:

I also wonder sometimes why I am doing this course, making my life [difficult]...he [husband] also asks sometimes "what is the point? You are a mother and you are doing the stuff and you didn't have enough time" (31).

Nevertheless, these students managed to cope through being part of a supportive student cohort.

\section{The third transition: learning and belonging}

\section{Understanding the university system}

The interviews with participants in their final years showed that there were a number of changes in how they understood the university's practices. Knowing the system and what was expected enabled them to become part of the community. By the beginning of their final year, the students had a greater depth of knowledge to draw on and a better understanding of what was required. This was partly to do with the time spent in the university because

You feel a lot more [committed] because you're doing more work and it matters more to you (02).

It was also about understanding that it was necessary to consider the whole learning experience by drawing on work from all their courses so that

Everything comes together (24).

Almost all of students said that getting to know both students and staff was the key to understanding the system because as one put it,

The university was a big scary place when you first come in...but now I'm the one wandering around...feeling comfortable (12). 
Staff played a large part in helping students feel comfortable, as long as they were perceived to be available, and this enabled students to feel that they could ask for support and it would be offered. But this might involve finding the right staff that you could engage with:

those you could approach and say, "look, I'm struggling here" (29)

Around half of the students also pointed out that they realised that staff valued the knowledge that they brought to their programme. This was very encouraging because, rather than their maturity being seen as a disadvantage,

there was a recognition of our knowledge as well as our practice experience and ability (38).

\section{Changing approaches to learning and studying}

Most found that they had changed their approaches to learning and studying by the time that they were in their final years. For example,

I became a bit more efficient at sifting through the material and organising what I needed... and being more confident about structuring the essay and about what you're putting together [39].

Around half of the students spoke of how they had learned from the feedback that they had been given and had come to understand:

that you really had to think... and get all the information... accurate. I'd got used to what the expectations were (30)

This also illustrates the changing expectations that the students had about the standard of their work, as one pointed out:

I learned how to argue and justify my points (02)

Students also realised how much independent study was required and took on the identity of the autonomous learner.

It's just having a quiet moment at home, reading through it all and finding out how it all fits together and where it all lies and just taking responsibility for doing it yourself, really (37).

Students also saw that they had to struggle with the complexities of competing arguments because

there are no clear answers...now [I know] it's more to do with how you perceive the question and with what you thought (30)

\section{Managing time}

A clear majority of students commented on their increasing ability to manage their work, life and study balance although this often meant that they had to

cut down on the social life [30] prioritise study by putting other things [such as the family] aside at critical times [27] or getting up early to do the work when you can [02]. 
This was not straightforward; however, for students with other commitments,

I have been working and I have three children and...I always am having to put them first, in terms of their home work and things and then I would do what I had to do much later on in the day (04).

Having a busy life meant that students had to

grab time whenever I get it, every last bit of it...I am quite good at saying that hour is good for that and that hour is not good for something else (38).

These practical strategies, developed over the lifetime of the degree, helped the students to make sense of the university's practices in ways that they had been unable to imagine, or engage with, in their first year.

A few students had experienced personal or family crises including family breakdowns, a diagnosis of cancer and difficulties at work but had managed to keep on going due to flexible staff support, increasing experience in workload management and support from family and friends. Student 33 reflected that she sometimes found that her course was so engaging that it helped her to forget for a while what was happening in the rest of her life.

\section{The final transition: changing selves}

\section{Staying in the system}

The participants that we interviewed 10 years on commented on the role played by staff in providing support that had enabled them to persist with their studies. There were a variety of ways in which staff could do this:

our tutor,... was really good at supporting us and everything was made easy and manageable (37).

Making it manageable was not the only benefit:

He [course leader] just got you keyed up and enthusiastic. He gave you the confidence to share your ideas and everything. He would say what do you mean by that, could you explain it...[It was] just that general kind of feeling about people caring for you (41).

Many students had complicated personal lives outside of the university, and staff were also crucial in responding to these issues and helping them to keep going. For example,

My youngest daughter went completely off the rails...the first three essays I had extensions on them all and $\mathrm{x}$ [name of course leader] said..., "you're going to struggle. You're just going to constantly be playing catch up. You've got to think about it". The staff...were supportive of me taking the year out, sorting out my daughter and then coming back, And then when I did...I passed everything else after that, so it was the best decision (12).

Staff needed to be available and sympathetic; otherwise, students internalised these problems and saw themselves as outside of the "normal" university community. Almost all the students identified one person that had been particularly helpful in enabling them to develop their relationship with the university. This could involve: 
picking the right people to ask [my] questions and...point me in the right direction (44)

It worked best where staff had

a good understanding that people were actually running homes, doing a job and trying to do [the degree] as well (33).

The students' perceptions of the extent of their reciprocal relationship and connectedness with particular individuals were crucial in this process.

I said to [course leader], I don't know if I can do it, I don't know if I've got the confidence; and he said, "yes, you can" (40).

When staff believed in them, students felt supported. This included having the confidence to share ideas, to have them listened to respectfully and to be able to achieve their goals.

I feel more confident because of all the things that I have achieved but in small steps. I've just become more confident in thinking...these things are not as scary as you think and they help with learning (37).

Not all students experienced this support, however. One student, who had withdrawn in her second year, contrasted the lack of support at the university in which this research was conducted with her subsequent experience at another university. She felt that much more support from staff at her first university would have helped her to understand and get help with the difficulties that she was having. She reported that at [x institution],

the tutorial system was really supportive; there were on-line forums, phone tutorials and very responsive tutors. You could send an email at midnight when you had a problem and the tutor would reply by the next morning (13).

This was a complete contrast to her original experience where she felt that no one really cared about her although she did now consider that at her first university:

I needed to be more proactive in getting support when I was struggling to understand something (13).

\section{Changing selves}

For many students, being able to succeed had involved overcoming their self-doubt. One student spoke about her struggle over final-year dissertation:

I sat going “who do you think you are?"... all the negative self-quotes and so that was a pretty low point until I managed to just get myself together (04).

Another reflected

I believe in myself a lot more now...I'm becoming more confident in myself. Instead of thinking "I'll never manage a degree" thinking "I did manage that degree" (41).

This student was particularly helped by

having a wee group in [place]... when at times you thought "no, I can't do this anymore" but we kind of gee'd each other along like a support group (41). 
Looking back, students reported that their experiences and relationships both enabled them to navigate the system and also to feel that they had gained full membership of the university.

The whole university experience-I just sucked it up like a sponge (04) and

I think there's that positivity about having knowledge and having the confidence to apply the knowledge that you've got to different situations (38).

One student commentated on the value of waiting until she was ready for university:

My head was full of parties and nonsense when I was 18...[so] I think I made a better student as a mature student. It was difficult at times, but I wouldn't have been ready for it before (40).

Part of this readiness was about the ability to develop the critical thinking skills that involved students in identifying and critiquing premises that they had previously taken for granted. For example,

The course has made me more reflective in practice, work and personal...from the content of the course [I learnt] to consider other people and their experiences and...now I don't assume anything (37).

For almost all, it opened up a love of learning:

I'm the kind of person that is always learning, I'm always thinking "what can I learn from that?" and I'm always pushing myself, thinking that I can do better. University opened up so many doors for me (30).

University was also important in extending students' understanding including

learning about myself (24), "widen[ing] your bubble from just thinking about you and your own wee issues...to other people (43), approaching things with a bit more knowledge" (44)

It also broadened experience:

I definitely came out of it at the end much more confident and able, and having experienced a lot of things (29).

A few students learnt from more negative experiences too as one said:

You learn better when you've had knocks, and to fail the odd essay is not the end of the world. You actually put in a better essay when you do your re-sit because you've had to really think about it and work out... where you went wrong (40).

\section{Family, personal and professional lives}

The students' reflections on their changed selves also demonstrated the impact on their family and personal lives:

It made me reflect on organising my time effectively, and spending quality time with my family' (02) and “it certainly had a positive impact on [my son] and he wanted to go there and he was very proud that his mum had been to University when a lot of his friends" mums hadn't" (41). Another suggested that: I have shown my children that you 
can learn at any age. You don't have to leave school and then just go to university.... If you're positive enough about it, you can go off and do it (12).

Around half spoke about how their changed understandings had an impact on their professional lives.

It got me thinking... about the bigger picture...looking at things in a different light, which helps with your...work life and your relationships' (43).

[University] opened my mind, being more open-minded benefitted me in regard to my work (41) and

It made me a better planner for children...Because you get knocks all the time, and things that don't work out, and you have to try again... and be quite fluent and adaptable (40).

\section{Discussion and conclusion}

In this paper, we have shown what a cohort of non-traditional students' perceived to be the key transitions that they experienced on entry to, and during, their university studies. We have argued that transitions are not one-off events that occur when students first enter universities but are part of an on-going process that develops over time and is affected by students' capacity to engage with, and become part of, the university community. Our argument has been framed by a socio-cultural perspective through which the four main transitions that the students experienced have been analysed as a dialectical relationship between them and the socially structured world of the university (Lave \& Wenger 1991).

Our findings from the first transition show that the differences that the students experienced between their FE institutions and the university impacted negatively on their self-confidence and dimmed their sense of excitement about their studies. The combination of leaving a familiar environment, more limited support from staff and peers, the uncertainty about what was expected of them academically and the delay in providing immediate feedback on their work meant that they felt that they no longer belonged and had difficulty in developing "an identity of participation" (Wenger 1998: 202). Their learning environment was no longer familiar or negotiable, and instead, they had to work hard to find effective ways of participating in the new knowledge practices of the university (Solomon 2007). As Hussey and Smith (2010) have pointed out, they were not yet able to understand and assimilate the tacit assumptions and practices of the disciplines that they were studying.

By the second transition, at the end of the first year, the students had generated more of a sense of belonging to the university through developing positive relationships, especially with fellow students. Friendships were particularly important when students were struggling, and shared external commonalities, such as being a "mature" student, helped bind people together. Moreover, as Scanlon et al. (2007) point out, working with peers helped the students to "begin to develop as the independent learners valued by the university" (239). At this stage too, a feeling of entitlement to participate could become transformed into a "right" when students were part of supportive networks and felt that they were coping academically. As they moved through their first year, students were more able to engage with staff, especially through the tutorials, as relationships developed and students' sense of not knowing gradually changed. These findings accord with other research that demonstrates the importance of developing social engagement, seeking help and information and interacting with other students in learning to fit into the university community (Brooman \& Darwent 2013; Devlin 2013). 
We have shown that by their third and final years, students had learned how to engage meaningfully with the university system. This was because, as other research has found (Bowles et al. 2014; Briggs et al. 2012), they were more willing to seek appropriate academic support and they were making more effort and, as a result, had developed a greater commitment to their studies. This transition was particularly helped by relationships with staff, and as students reconceptualised their understandings of what university was about, they crafted new learning identities through this situated action with others (Scanlon et al. 2007). By this stage in their university careers, the students had also changed their conceptions of how learning and teaching should take place and made the transition from a passive and dependent learner to an active and autonomous learner. As Byrne \& Flood (2005) suggest, learning approaches "are dynamic and are influenced by the learning environment and an array of personal factors including students' prior learning experiences" (212). The students in our study had successfully aligned their past experiences of learning and found effective ways of fully engaging in the knowledge practices of the university through "develop[ing] an identity of participation" (Wenger 1998, 202). A key aspect of this was becoming more meaning orientated in their approaches to learning (Donche et al. 2010) as well as taking intellectual risks in their engagement with "dominant discourses and official knowledges" (Saltmarsh \& Saltmarsh 2008, 622).

Throughout their time at university, the students' commented on the impact of their studies on their identities, but this was particularly explicit in the data from the retrospective interviews. It is clear from students' reflections on their overall experience that their final transition was a social and relational process, where they brought a cluster of beliefs about themselves and their capabilities that were reconceptualised over their learning journeys. This was the result of the development of a set of social relations with staff and peers that had changed their position from one of dependence to one of greater independence (Clayton et al. 2009) and led them to change the evaluations that they had of their capabilities. Moreover, the pedagogical relationships that they had developed with staff fostered the dispositions and qualities that allowed them to gain confidence in their own knowledge and learn to "appropriately express disagreement" (Devlin 2013, 942). Our findings also show, as Shin $(2002,123)$ argues, that this relationship required students to feel that staff were "both available... and connected" to them otherwise, as illustrated by student 13 , a reciprocal relationship could not develop between the staff member and the student.

Another aspect of the relationships that were formed through engaging with staff and peers was that students were able to move towards a more critical being, with wider horizons of possibility that opened up opportunities for them (Leese 2010; Scanlon et al. 2007). Moreover, because they had fully participated in the development of ideas and meanings within the university and had a sense of ownership of meaning making (Solomon 2007, 90), they were able to take this thinking into their personal and professional lives. The process that they had gone through in reliving and integrating their past and present experiences enabled them to see the bigger picture, and so, they were able to see themselves and the world in new ways that had a strong impact on the other aspects of their lives.

In conclusion, this paper has made a contribution to the literature through showing what a cohort of non-traditional students' perceived to be their key transitions. Although the set of critical moments that they experienced varied over time, there were a number of commonalities that made these transitions easier: peer support, staff-student interaction, managing academically and building self-esteem. There was also a strong impact on their identities as 
a result of their university experiences, and this manifested itself through different ways of dealing with issues in their personal and professional lives.

Our findings have implications for the support and retention of students that are making transitions. We have shown that the conditions need to be created where students feel connected to the institution, the staff and their peers. This involves building pedagogical relationships of trust with staff in order for students to achieve confidence in the techniques and tools that are characteristic of university practice and recognising the importance of forming supportive relationships. In this way, students are able to build up their self-esteem, moving from thinking that they are going to fail towards a belief that they could succeed and these changes have continued to impact on their identities as they move through their lives.

There are some limitations to be considered. Firstly, the study began over 10 years ago. Since then, there have been significant changes to policy and practice in response to feedback from students, changes in the student cohorts and new ideas about teaching and learning, particularly in the key area of student support. Secondly, the study was located in one Scottish university and relied on a small self-selecting sample that was mainly female and drawn from a limited range of programmes. It might be argued that this university (and this sample) is not representative of "non-traditional students" as other universities understand this term. We can only acknowledge these realities as inevitable parameters to our study while, at the same time, highlighting that it is the special situation of these students in this university, and their views expressed over time, which brings most insight into our understanding of transitions in higher education overall.

Acknowledgements We are grateful to our helpful referees and to the participants in our study for giving so freely of their time.

Open Access This article is distributed under the terms of the Creative Commons Attribution 4.0 International License (http://creativecommons.org/licenses/by/4.0/), which permits unrestricted use, distribution, and reproduction in any medium, provided you give appropriate credit to the original author(s) and the source, provide a link to the Creative Commons license, and indicate if changes were made.

\section{References}

Bathmaker, A. M., \& Thomas, W. (2009). Positioning themselves: an exploration of the nature and meaning of transitions in the context of dual sector FE/HE institutions in England. J Furth High Educ, 33(2), 119-130. doi:10.1080/03098770902856652.

Bowles, A., Fisher, R., McPhail, R., Rosenstreich, D., \& Dobson, A. (2014). Staying the distance: students' perceptions of enablers of transition to higher education. Higher Education Research \& Development, 33(2), 212-225. doi:10.1080/07294360.2013.832157.

Braun, V., \& Clarke, V. (2006). Using thematic analysis in psychology. Qual Res Psychol, 3(2), 77-101.

Briggs, A. R. J., Clark, J., \& Hall, I. (2012). Building bridges: understanding student transition to university. Qual High Educ, 18(1), 3-21. doi:10.1080/13538322.2011.614468.

Brooman, S., \& Darwent, S. (2013). Measuring the beginning: a quantitative study of the transition to higher education. Stud High Educ, 39(9), 1523-1541. doi:10.1080/03075079.2013.801428.

Byrne, M., \& Flood, B. (2005). A study of accounting students' motives, expectations and preparedness for higher education. Journal of Further and Higher Education 29(2), 111-124.

Christie, H., Tett, L., Cree, V. E., Hounsell, J., \& McCune, V. (2008). A real rollercoaster of confidence and emotions': learning to be a university student. Stud High Educ, 33(5), 567-581.

Clayton, J., Crozier, G., \& Reay, D. (2009). Home and away: risk, familiarity and the multiple geographies of the higher education experience. International Studies in Sociology of Education, 19(3-4), 157-174. 
Cree, V. E., Croxford, L., Halliwell, J., Iannelli, C., Kendall, L., \& Winterstein, D. (2006). Widening participation at an ancient Scottish university. Scottish Affairs, 56, 102-130.

Crossan, B., Field, J., Gallacher, J., \& Merrill, B. (2003). Understanding participation in learning for nontraditional adult learners: learning careers and the construction of learning identities. Br J Sociol Educ, 24(1), 55-67. doi:10.1080/01425690301907.

Devlin, M. (2013). Bridging socio-cultural incongruity: conceptualising the success of students from low socioeconomic status backgrounds in Australian higher education. Stud High Educ, 38(6), 939-949. doi:10.1080 /03075079.2011.613991.

Donche, V., Coertjens, L., \& Van Petegem, P. (2010). Learning pattern development throughout higher education: a longitudinal study. Learning and Individual Differences, 20(3), 256-259. doi:10.1016/j.lindif.2010.02.002.

Field, J. (2004).Articulation and credit transfer in Scotland: taking the academic highroad or a sideways step in a ghetto? Journal of Access Policy and Practice, (2) 85-99.

Gale, T., \& Parker, S. (2014). Navigating change: a typology of student transition in higher education. Stud High Educ, 39(5), 734-753. doi:10.1080/03075079.2012.721351.

Griffiths, S., Winstanley, D., \& Gabriel, Y. (2005). Learning shock: the trauma of return to formal learning. Manag Learn, 36(3), 275-297.

Hassan, E. (2005). Recall bias can be a threat to retrospective and prospective research designs. The Internet Journal of Epidemiology, 3(2), 1-7.

Higgs, J., Horsfall, D., \& Byrne-Armstrong, H. (2001). Critical moments in qualitative research. USA: ELSEVIER SCIENCE (MO).

Hodkinson, P. (2005). Learning as cultural and relational: moving past some troubling dualisms. Camb J Educ, 35(1), 107-119. doi:10.1080/0305764042000332524.

Hussey, T., \& Smith, P. (2010). Transitions in higher education. Innovations in Education and Teaching International, 47(2), 155-164. doi:10.1080/14703291003718893.

Lave, J., \& Wenger, E. (1991). Situated learning: legitimate peripheral participation. Cambridge: Cambridge University Press.

Leese, M. (2010). Bridging the gap: supporting student transitions into higher education. J Furth High Educ, 34(2), 239-251. doi:10.1080/03098771003695494.

Reay, D., Crozier, G., \& Clayton, J. (2010). 'Fitting in' or 'standing out': working-class students in UK higher education. Br Educ Res J, 36(1), 107-124.

Saltmarsh, D., \& Saltmarsh, S. (2008). Has anyone read the reading? Using assessment to promote academic literacies and learning cultures. Teach High Educ, 13(6), 621-632.

Scanlon, L., Rowling, L., \& Weber, Z. (2007). 'You don't have an identity...you are just lost in the crowd': forming a student identity in the first-year transition to university. J Youth Stud, 10(2), 223-241. doi:10.1080 /13676260600983684.

Scottish Funding Council (2015). Learning for all: measures of success: statistical publication SFC/ST/06/2015. Edinburgh: SFC.

Shin, N. (2002). Beyond interaction: the relational construct of 'transactional presence'. Open Learning: The Journal of Open, Distance and e-Learning, 17(2), 121-137. doi:10.1080/02680510220146887.

Solomon, Y. (2007). Not belonging? What makes a functional learner identity in undergraduate mathematics? Stud High Educ, 32, 79-96.

Wenger, E. (1998). Communities of practice: learning, meaning and identity. Cambridge: Cambridge University Press. 